\title{
Vegetables and fruit intake and cancer mortality in the Hiroshima/ Nagasaki Life Span Study
}

\author{
C Sauvaget*,', J Nagano',2, M Hayashi', E Spencer ${ }^{3}$, Y Shimizu' and N Allen ${ }^{3}$ \\ 'Department of Epidemiology, Radiation Effects Research Foundation, 5-2 Hijiyama Park, Minami-ku, Hiroshima 732-08I 5, Japan; ${ }^{2}$ Institute of Health \\ Science, Kyushu University, Kasuga Park 6-I, Kasuga, Fukuoka 816-8580, Japan; ${ }^{3}$ Cancer Research UK, Epidemiology Unit, Gibson Building, Radcliffe \\ Infirmary, Oxford OX2 6HE, UK
}

\begin{abstract}
The association between green-yellow vegetables and fruit consumption and risk of cancer death was investigated in a prospective study of 38540 men and women who were atomic-bomb survivors in Hiroshima and Nagasaki, Japan. Study participants completed a dietary questionnaire in 1980-1981 and were followed-up for cancer deaths until March 1998, during which time 3136 cancer deaths were identified. Daily or almost daily fruit consumption was associated with a significant $12 \%$ reduction in total cancer mortality $(R R=0.88 ; 95 \% \mathrm{Cl}, 0.80-0.96$ for daily intake compared with intake once per week or less). Daily or almost daily greenyellow vegetables consumption was associated with a marginally significant $8 \%$ reduction in total cancer mortality $(0.92 ; 0.94-1.01)$. Green-yellow vegetables consumption was associated with a significant reduction in liver cancer mortality $(0.75 ; 0.60-0.95)$. Fruit consumption was associated with a significantly reduced risk of stomach cancer and lung cancer mortality (0.80; 0.65-0.98). Greenyellow vegetables and fruit consumption was associated with a reduction in oesophageal cancer, but these associations were not statistically significant. Neither green-yellow vegetables nor fruit consumption was associated with colorectal cancer or breast cancer mortality. These results support the evidence that daily consumption of fruit and vegetables reduces the risk of total cancer, and specifically cancers of the stomach, liver, and lung.

British Journal of Cancer (2003) 88, 689-694. doi:10.1038/sj.bjc.6600775 www.bjcancer.com
\end{abstract}

(C) 2003 Cancer Research UK

Keywords: cancer mortality; diet; fruit and vegetables; longitudinal study

Since the early 1980 s, cancer has been the principal cause of death in Japanese men and women (Health Statistics Foundation, 2000). Although the total cancer mortality rate in Japan is similar to that of other developed countries, mortality rates for specific cancers differ widely. For example, in 2000, the mortality rate for stomach cancer was several-fold higher in Japan (Japan M: 31.2 per 100000 population; F: 13.8 ) than in the US (M: $4.5 ; \mathrm{F}: 2.3)$ or the UK (M: 10.1 ; F: 4.8); conversely, female breast cancer was up to three-fold lower in Japan than in Western countries (Japan: 7.7; US: 21.2; UK: 26.8) (Ferlay et al, 2001). Lifestyle, and in particular diet, has been hypothesised to explain partly the differences in these cancer rates between countries (Tominaga, 1985).

Diet-related factors are thought to account for between 20 and $30 \%$ of all cancers (Doll and Peto, 1981). However, few specific dietary factors have been established, except for alcohol intake and cancers of the oral cavity, pharynx, larynx, oesophagus, liver, and breast, and salt intake and cancer of the stomach (World Health Organization, 1977; Smith-Warner et al, 1998). Fruit and vegetables have been considered to be as beneficial for several cancer sites, including cancers of the stomach, colon and rectum, lung, pancreas, and bladder, although the epidemiological evidence is inconsistent, particularly for hormone-dependent cancers such as the prostate and breast cancer (Branca et al, 2001).

*Correspondence: Dr Catherine Sauvaget; E-mail: sauvaget@rerf.jp Received 5 November 2002; revised 27 November 2002; accepted 2 December 2002
As longitudinal studies of vegetables and fruit and cancer in Japan are scarce (Hirayama, 1986; Kobayashi et al, 2002), this study aimed to examine the association between green-yellow vegetables and fruit consumption on the risk of the most common cancer deaths in a prospective cohort study in Japan.

\section{METHOD}

\section{Study population}

The Life Span Study (LSS) is a prospective study of 120321 subjects including atomic-bomb survivors and nonexposed controls. The Atomic Bomb Casualty Commission (ABCC), followed by the Radiation Effects Research Foundation (RERF), initiated the follow-up in 1950, and regularly monitors the causes of death among the participants through death certificates and other vital status surveys (Pierce et al, 1996).

A mail survey was carried out among the 55650 LSS subjects who were alive as of 1 September 1978 (Radiation Effects Research Foundation, 1978), and of whom 40349 persons completed the questionnaire (response rate of $72.5 \%$ ). Completion of the mail survey was effective as from 1 January 1980 for men, and 1 February 1981 for women, during which time 525 persons had died. After exclusion of 1284 cancer cases at baseline based on the information of incidence cases from the Hiroshima and Nagasaki tumour registries, the study population consisted of 38540 
participants (14873 men and 23667 women). The mean age at baseline was 56 years old (range 34-103).

\section{Dietary assessment}

The mailed lifestyle questionnaire included questions on past medical history, smoking and drinking habits, marital status, reproductive history, occupation, education, and 22 dietary items, which assessed the average frequency of intake over the previous year (Nagano et al, 2000). The validity of the food-frequency questionnaire has been previously reported (Sauvaget et al, 2002).

On the food-frequency questionnaire, vegetable intake was limited to green-yellow vegetables, such as pumpkin, carrot, and spinach, and fruit intake referred to total fruit consumption.

For the analyses, green-yellow vegetables and fruit consumption were classified into three frequency categories: 'once per week or less', '2-4 times per week', and 'daily or almost daily'. A subanalysis showed that the mean intake of those with missing data on green-yellow vegetables and fruit consumption was similar to the intake of those who ate these foods once per week or less (Sauvaget et al, 2002). We therefore included participants with missing data with those who stated intake of fruit and vegetables as once per week or less (3465 persons with missing information on vegetables frequency intake, and 2257 persons on fruit intake).

\section{Follow-up/identification of cancer deaths}

Follow-up for mortality was linked with the Japanese nationwide family registration system (Koseki). The Koseki provides complete mortality ascertainment for the LSS cohort members residing in Japan. The cause of death was coded according to the International Classification of Diseases, Ninth and Tenth Revisions (ICD-9, ICD10) (World Health Organization, 1977). The start of the follow-up was assumed to be 1 January 1980 for men and 1 February 1981 for women because the exact dates of receipt of the completed questionnaires were not recorded. The end of the follow-up was defined as the date of death, or 31 March 1998, whichever came first.

\section{Statistical analysis}

The baseline characteristics of the study population were compared according to the intake of green-yellow vegetables and fruit using the $\chi^{2}$ test for categorical variables and analysis of variance for continuous variables.

Analyses of the mortality risks were based on multiplicative hazard function models. Relative hazards were computed using the Cox regression methods and confidence intervals were based on the Wald statistics. Age was the primary time scale in all analyses.

Relative risks were estimated for the categories of green-yellow vegetables intake and fruit intake. Baseline rates were adjusted for sex, age (continuous), city (Hiroshima, Nagasaki), radiation dose received by the corresponding organ (continuous), smoking habits (never, current, past), alcohol habits (never, current, past), education level (junior high school or less, high school, junior college or more), and body mass index $\left(\mathrm{BMI}=\right.$ weight $/$ height $\left.^{2}\right)$ (continuous). A test for trend was performed to assess statistical significance across exposure categories by including ordinal terms for each category of intake and entering the variable as a continuous term in the regression model. Lung cancer mortality risks were further stratified by sex and smoking status. For this analysis, current male smokers were dichotomised into those who smoked 20 cigarettes or less per day, and those who smoked more than 20 cigarettes per day. The number of women past-smokers was too small to allow for separate analysis. Relative risks of a specific death as compared to staying alive were calculated using the SAS PHREG procedure (SAS Institute, 2001).

\section{RESULTS}

During a median follow-up time of 16 years, a total of 3136 cancer deaths were identified, which largely comprised cancer of the stomach $(N=617)$, liver $(N=555)$, lung $(N=563)$, and colorectum $(N=226)$. On average, women ate green-yellow vegetables and fruit more frequently than men, and never-smokers had a higher consumption of vegetables and fruit than current smokers. Current drinkers ate vegetables and fruit less frequently than neverdrinkers, and a high frequency of vegetable and fruit intake was associated with a high education. The mean radiation dose was similar between all categories of vegetable and fruit intake (Table 1).

The relative risks for cancer mortality according to the consumption of green-yellow vegetables and fruit for the total cohort are presented in Table 2. A daily intake of green-yellow vegetables was associated with a marginally significant $8 \%$ reduction in total cancer mortality compared with those who consumed vegetables once per week or less. However, green-yellow vegetables consumption was associated with a significant $25 \%$ reduction in liver cancer, with a significant dose-response relationship. Compared with those who ate fruit once per week or less, a daily intake of fruit was significantly associated with a $12 \%$ reduction in total cancer mortality, and a $20 \%$ reduction in stomach and lung cancer mortality. A daily fruit intake was also associated with a $43 \%$ reduced risk of cancer of the oesophagus, but this was not statistically significant. Vegetables and fruit intake was not associated with death from cancer of the colorectum, gall bladder, pancreas, or breast.

Mortality risks were also performed for men and women separately (data not shown). An almost daily consumption of green-yellow vegetables and fruit was associated with a significant 28 and $35 \%$ reduction in stomach cancer mortality for women only. And daily fruit consumption was associated with a significant $32 \%$ reduced risk of lung cancer in men, but no association was found in women.

Relative hazards for fruit consumption were adjusted for greenyellow vegetables intake and vice versa. Furthermore, other food items that were significantly associated with each outcome were also included in the model. However, these adjustments did not materially alter the risk estimates (data not shown). For breast cancer, additional adjustment for age at menarche, age at first birth, parity, breast-feeding, menopausal status, personal history of breast adenoma, and family history of breast cancer also did not materially alter the risk estimates for vegetables and fruit intake (data not shown).

The association between vegetables and fruit intake and risk of lung cancer mortality was stratified by smoking status because smoking may confound the association between vegetables and fruit intake and lung cancer risk (Table 3). Although there were very few lung cancer deaths among nonsmoking men, a daily fruit intake was associated with a significantly reduced risk among both nonsmokers and smokers, whatever the number of cigarettes smoked. In nonsmoking women, a high intake of green-yellow vegetables was also associated with a reduced risk of lung cancer, although this association was not statistically significant, and was not observed among men.

\section{DISCUSSION}

There are limited epidemiological data on the potential protective role of fruit and vegetables intake on cancer risk among Asian populations. This large prospective study, with 18 years of followup, found that a daily intake of fruit was associated with a significantly reduced risk of total cancer and a reduced risk of stomach cancer and lung cancer. A daily intake of green-yellow vegetables was associated with a marginally reduced risk of total 
Table I Baseline characteristics of the study population by tertile of green-yellow vegetables and fruit consumption

\begin{tabular}{|c|c|c|c|c|c|c|c|c|}
\hline & \multicolumn{4}{|c|}{ Green-yellow vegetables } & \multicolumn{4}{|c|}{ Fruit } \\
\hline & \multicolumn{3}{|c|}{ Category } & $P$-value* & \multicolumn{3}{|c|}{ Category } & $P$-value* \\
\hline Serving frequency & $0-1$ week $^{-1}$ & $2-4$ week $^{-1}$ & Daily & & $0-1$ week $^{-1}$ & $2-4$ week $^{-1}$ & Daily & \\
\hline Number of subjects & 12397 & 16710 & 9433 & & 9256 & 12111 & 17173 & \\
\hline Radiation dose mSv (mean) & 117.1 & 112.9 & 108.1 & 0.085 & $|16|$. & 115.7 & 109.6 & 0.115 \\
\hline Age (year) (mean) & 57.1 & 54.8 & 56.8 & 0.001 & 57.3 & 54.7 & 56.3 & 0.001 \\
\hline $\mathrm{BMI} \mathrm{kg} \mathrm{m}^{-2}$ (mean) & 17.9 & 20.4 & 20.2 & 0.001 & 17.2 & 20.2 & 20.4 & 0.001 \\
\hline \multicolumn{9}{|l|}{ Smoking habits } \\
\hline Never (\%) & 26.6 & 45.1 & 28.3 & 0.001 & 16.5 & 28.3 & 55.2 & 0.001 \\
\hline Past (\%) & 39.8 & 42.0 & 18.3 & & 34.1 & 37.4 & 28.5 & \\
\hline Current (\%) & 32.6 & 42.3 & 25.1 & & 27.0 & 33.3 & 39.7 & \\
\hline \multicolumn{9}{|l|}{ Alcohol habits females } \\
\hline Never (\%) & 26.5 & 45.0 & 28.6 & 0.001 & 16.9 & 27.3 & 55.8 & 0.001 \\
\hline Current (\%) & 29.3 & 44.9 & 25.7 & & 19.1 & 28.2 & 52.7 & \\
\hline \multicolumn{9}{|l|}{ Education level } \\
\hline Low (\%) & 36.4 & 42.2 & 21.4 & 0.001 & 28.1 & 32.8 & 39.1 & 0.001 \\
\hline Middle (\%) & 29.2 & 45.1 & 25.8 & & 20.3 & 30.4 & 49.3 & \\
\hline High (\%) & 24.9 & 42.8 & 32.3 & & 18.9 & 32.0 & 49.1 & \\
\hline
\end{tabular}

*Test for homogeneity of characteristics between categories of green-yellow vegetables and fruit consumption.

$\chi^{2}$ (sex, smoking, drinking, and education) and analysis of variance.

Table 2 Relative risk according to the level of consumption of green-yellow vegetables and fruit

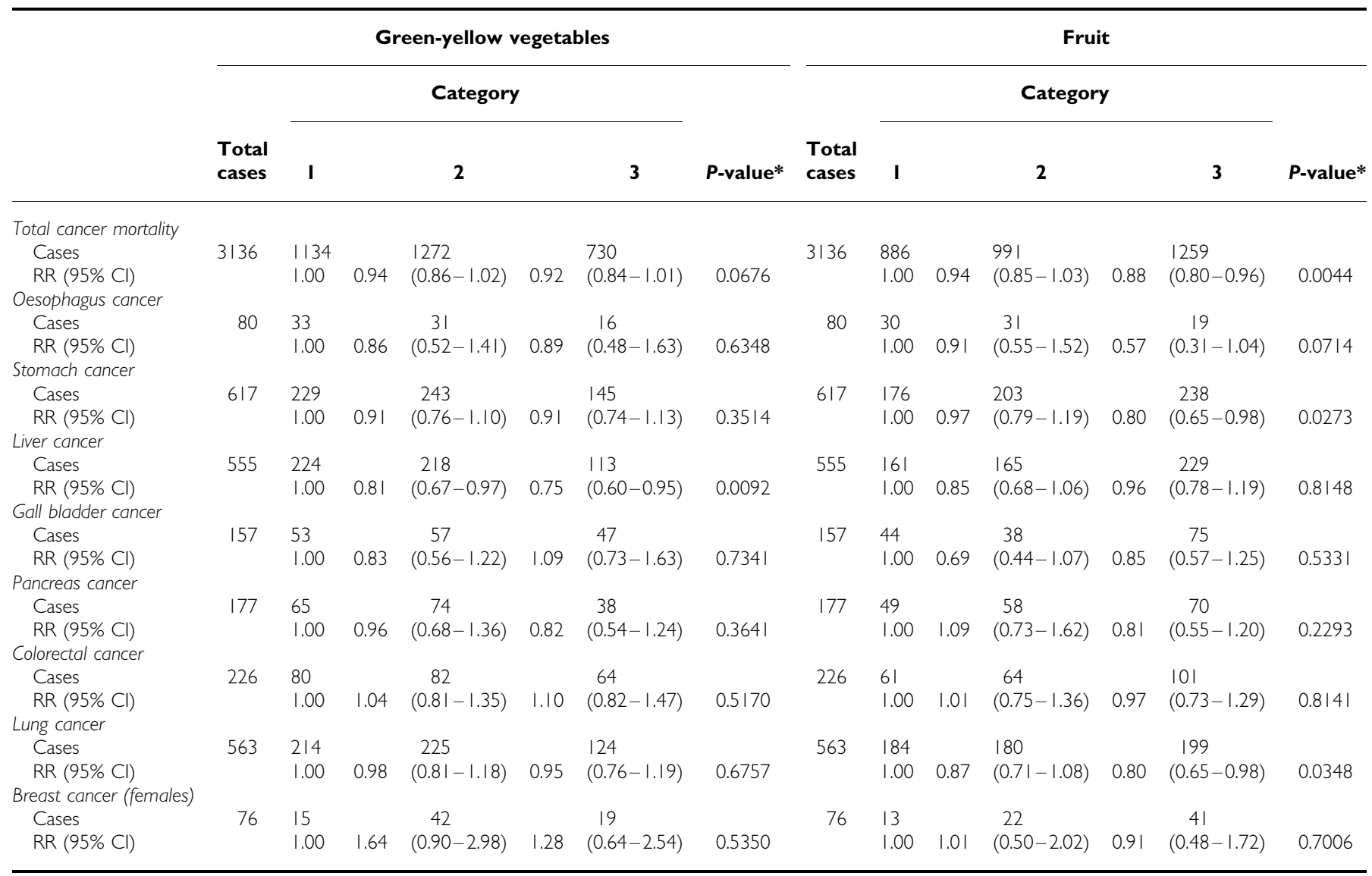

*Test for trend; relative risk adjusted for sex, age, radiation dose, city, BMI, smoking status, alcohol habits, and education level. 
Table 3 Green-yellow vegetables and fruit consumption and lung cancer risk according to sex and smoking status

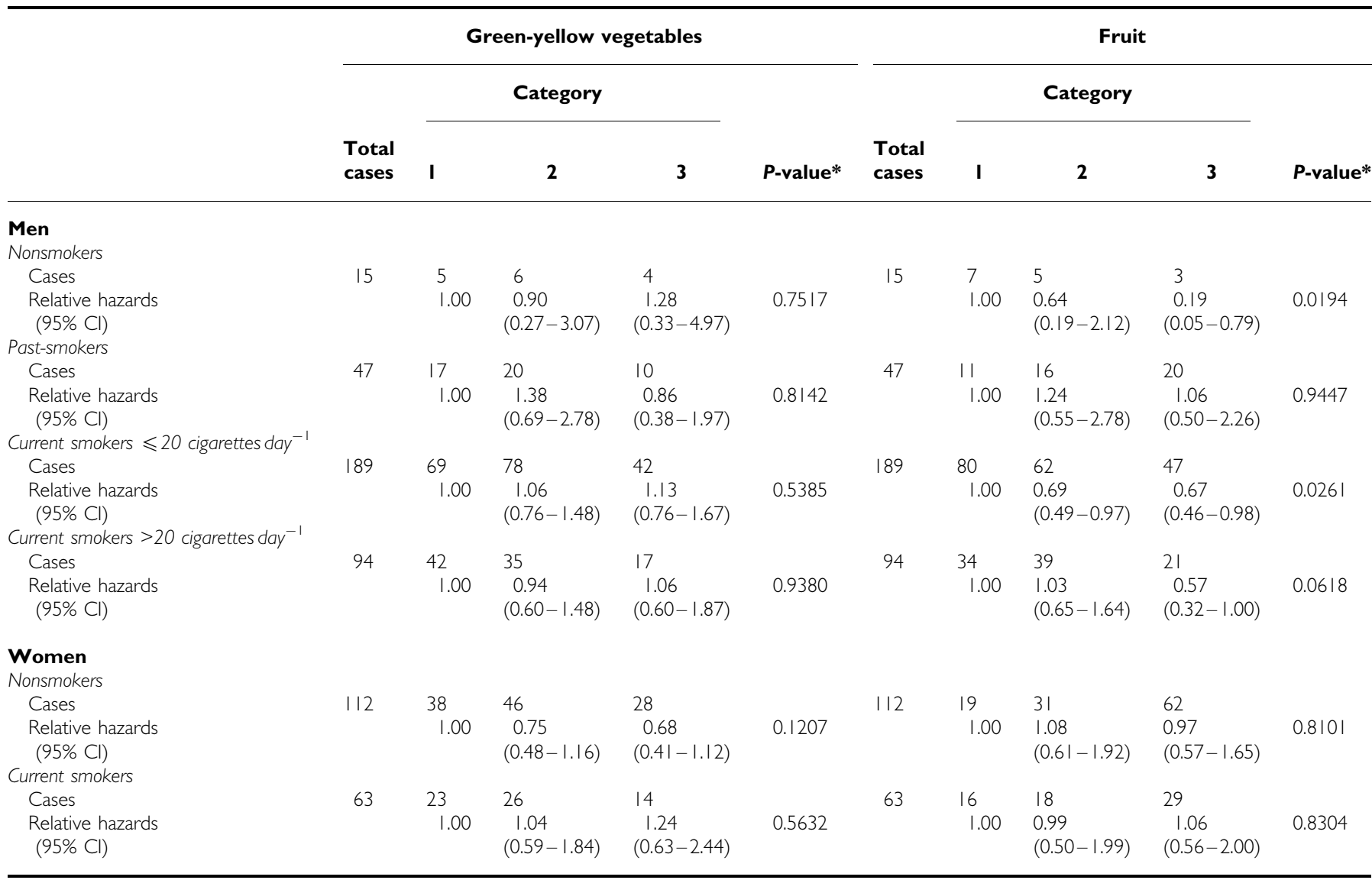

*Test for trend; relative hazards adjusted for age, radiation dose, city, BMI, smoking status, alcohol habits, and education level.

cancer mortality and a significantly reduced risk of liver cancer mortality.

The potential protective role of vegetables and fruit intake on cancer risk has been extensively studied over the past two decades (World Cancer Research Fund and American Institute for Cancer Research, 1997), and there is consistent evidence that a high intake of fruit and/or vegetables may protect against cancers of the upper gastro-intestinal tract (including stomach cancer). In the present study, vegetables were limited to green-yellow vegetables, defined as vegetables containing more than $1000 \mathrm{IU}$ of carotene per $100 \mathrm{~g}$ (carrots, spinach, pumpkin, lettuce, asparagus, parsley, etc.) (Hirayama, 1980). In addition to $\beta$-carotene, green-yellow vegetables and fruit are a rich source of vitamin $C$, vitamin $E$, minerals, and dietary fibres. These nutrients are well known for their immune-enhancing properties and antioxidant effects, especially as in vivo markers of lipid peroxidation (Zhang et al, 1995; Steinmetz and Potter, 1996; Broekmans et al, 2000; Arab et al, 2001). They may also act as inhibitors of cancer initiation, promotion, and progression (Hirayama, 1986).

It is well known that high fruit and vegetable intakes are protective factors for upper aero-digestive cancers (Steinmetz and Potter, 1991; Guo et al, 1994). Our results are consistent with these findings, although the small number of oesophageal cancers limited the power to detect an association with this cancer site.

Stomach cancer still represents a major cause of cancer mortality in Japan (Health Statistics Foundation, 2000) and in addition to infection with Helicobacter pylori (Adam and Efron, 1989), a high salt intake increases risk (Kato et al, 1992) and a high intake of fruit and vegetables may reduce risk (Japanese Epidemiological Association on Cancer, 1998). In the present study, the protective effect of fruit and vegetables on stomach cancer was stronger in women than in men. Different exposures between men and women to other stomach cancer risk factors, such as salted or smoked food, smoking, alcohol, and/or stress factors may play a role (Hirayama, 1980; Branca et al, 2001), although adjustment for these factors made little difference to results.

There is limited data on the association between fruit and vegetables intake and risk of gall bladder cancer. Our study, based on 157 cases, found no strong evidence for an association between green-yellow vegetables or fruit intake. This is consistent with a previous cohort mortality study conducted in Japan (Hirayama, 1981), although case-control studies have reported significant protective effects for fruit and vegetables (Kato et al, 1989) and intakes of vitamins C and E (Zatonski et al, 1992). Our study also found no evidence for a strong association between fruit and vegetables consumption and pancreas cancer mortality, which is consistent with other cohort studies (Hirayama, 1981; Zheng et al, 1993; Shibata et al, 1994; Ziegler et al, 1996; Stolzenberg-Solomon et al, 2002), although the numbers of cases in all of these studies, including ours, may be too small to detect a moderate association.

Liver cancer and particularly hepatocellular carcinoma is a common cancer in Asia, although rare in North American and Western countries. Until now, the role of diet has been little studied. Our finding that a high intake of green-yellow vegetables significantly decreased the risk of primary liver cancer mortality is consistent with other studies in Japan (Hirayama, 1990), Taiwan (Yu et al, 1995), and Italy (La Vecchia et al, 1988).

The suggested beneficial effect of vegetables consumption on the risk of colorectal cancer, specifically green leafy vegetables or cruciferous vegetables and their fibre content, has mainly derived from case-control studies (Block et al, 1992), but the results of 
recent large prospective studies have been inconsistent showing either protective effects or no association (Steinmetz et al, 1994; Singh and Fraser, 1998; Fuchs et al, 1999; Michels et al, 2000; Voorrips et al, 2000; Terry et al, 2001). Indeed, we found no evidence that a high intake of fruit or vegetables is associated with a reduced risk of colorectal cancer death. Further, results from randomised controlled trials have not shown that a diet low in fat and high in fibre and fruit and vegetables can reduce the recurrence of colorectal adenomas (Alberts et al, 2000; BonithonKopp et al, 2000; Schatzkin et al, 2000).

Although breast cancer mortality rates in Japan have steadily increased over the past three decades, the rates are still much lower than that in Western countries (Ferlay et al, 2001). It has been suggested that this difference might be partly explained by dietary factors, such as dietary fat or isoflavones (Wynder, 1977; Key et al, 1999). The evidence that a high intake of fruit and vegetables is protective against breast cancer is inconsistent (World Cancer Research Fund and American Institute for Cancer Research, 1997), and our findings are in agreement with other cohort studies that suggest that fruit and vegetables intake are not strong dietary determinants of breast cancer mortality in Asian (Hirayama, 1978) or Western women (Verhoeven et al, 1997). Other cohort studies have also found no association between vitamin $\mathrm{C}$ intake and/or $\beta$ carotene intake and breast cancer risk (Hunter et al, 1993; Rohan et al, 1993). However, all these studies included women in middle age or older ( $40-80$ years old) and there is little evidence on the effects of diet at a younger age, when breast carcinogenesis may be initiated (Hill, 1997). The findings from these studies therefore suggest that dietary antioxidants may not have a protective effect at a late stage of breast carcinogenesis. Prospective studies on dietary factors during childhood or adolescence may, therefore, be more appropriate to identify the dietary determinants of breast carcinogenesis.

Lung cancer mortality has dramatically increased in Japan in the last decade and, although it is still below the rates of most developed countries, is now the leading cause of cancer death in men, and the third cause of death in women (Health Statistics Foundation, 2000). Although tobacco smoking is the leading cause of lung cancer, a high consumption of vegetables, fruit, and carotenoids have been associated with a decreased risk of lung cancer (Feskanich et al, 2000; Le Marchand et al, 2000; Michaud et al, 2000; Holick et al, 2002). However, randomised controlled trials with supplementation of $\beta$-carotene and retinol among American male physicians, and male Finnish smokers failed to find any beneficial effect (Hennekens et al, 1996; Omenn et al, 1996). In our study, the protective effect of fruit on lung cancer mortality

\section{REFERENCES}

Adam YG, Efron G (1989) Trends and controversies in the management of carcinoma of the stomach. Surg Gynecol Obstet 169: 371-385

Alberts DS, Martinez ME, Roe DJ, Guillen-Rodriguez JM, Marshall JR, van Leeuwen JB, Reid ME, Ritenbaugh C, Vargas PA, Bhattacharyya AB, Earnest DL, Sampliner RE (2000) Lack of effect of a high-fiber cereal supplement on the recurrence of colorectal adenomas. Phoenix Colon Cancer Prevention Physicians' Network. N Engl J Med 342: 1156-1162

Arab L, Steck-Scott S, Bowen P (2001) Participation of lycopene and betacarotene in carcinogenesis: defenders, aggressors, or passive bystanders? Epidemiol Rev 23: $211-230$

Block G, Norkus E, Hudes M, Mandel S, Helzlsouer K (2001) Which plasma antioxidants are most related to fruit and vegetable consumption? $A m \mathrm{~J}$ Epidemiol 154: $1113-1118$

Block G, Patterson B, Subar A (1992) Fruit, vegetables, and cancer prevention: a review of the epidemiological evidence. Nutr Cancer 18: 1 29

Bonithon-Kopp C, Kronborg O, Giacosa A, Rath U, Faivre J (2000) Calcium and fibre supplementation in prevention of colorectal adenoma was stronger among male smokers compared with past smokers. Although no protective effect was observed in women smokers, a high consumption of green-yellow vegetables tended to decrease the lung cancer mortality in nonsmoking women, of which $70 \%$ were because of adenocarcinoma of the lung. This histological type is not related to cigarette smoking but has been associated with hormonal factors and dietary fat (Payne, 2001).

One limitation of this study is that participants might have changed their diet over the relatively long follow-up time. The validation of the questionnaire showed only moderate correlations with the 24-h diary used as reference method (Sauvaget et al, 2002). Also, the dietary questionnaire did not include information on portion sizes and was limited to certain foods, so total energy and nutrient intakes could not be calculated. Making no allowance for total energy intake may increase variation in the consumption of specific foods, and attenuate any true association between vegetable and fruit intake and cancer mortality risk. However, it has recently been demonstrated that the correlation between fruit and vegetables consumption and plasma antioxidants was not altered after adjustment for dietary energy intake (Block et al, 2001), suggesting that between-person variation in energy intake does not unduly influence fruit and vegetables intake. It should also be noted that by covering only green-yellow vegetables, the questionnaire may have missed an effect of total vegetable consumption on cancer mortality.

On the other hand, the strength of the study lies in the large study population and the long follow-up period. Although the study population is unique in that they are atomic-bomb survivors, radiation exposure was related neither to green-yellow vegetables nor fruit consumption, so the present results may be relevant to other populations.

In conclusion, the present longitudinal study in a Japanese population adds some weight to the hypothesis that a daily consumption of green-yellow vegetables and fruit is associated with a reduced risk of cancer mortality, specifically cancers of the stomach, liver, and lung.

\section{ACKNOWLEDGEMENTS}

This publication is based on research performed at the Radiation Effects Research Foundation (RERF), Hiroshima and Nagasaki, Japan. RERF is a private nonprofit foundation funded equally by the Japanese Ministry of Health, Labour and Welfare, and the US Department of Energy through the National Academy of Sciences. recurrence: a randomised intervention trial. European Cancer Prevention Organisation Study Group. Lancet 356: $1300-1306$

Branca F, Hanley AB, Pool-Zobel B, Verhagen H (2001) Biomarkers in disease and health. Br J Nutr 86(Suppl 1): S55 - S92

Broekmans WM, Klopping-Ketelaars IA, Schuurman CR, Verhagen H, van den Berg H, Kok FJ, van Poppel G (2000) Fruits and vegetables increase plasma carotenoids and vitamins and decrease homocysteine in humans. J Nutr 130: $1578-1583$

Doll R, Peto R (1981) The causes of cancer: quantitative estimates of avoidable risks of cancer in the United States today. J Natl Cancer Inst 66: $1191-1308$

Ferlay J, Bray F, Pisani P, Parkin DM (2001) GLOBOCAN 2000: Cancer Incidence, Mortality and Prevalence Worldwide, Version 1.0. Lyon: IARC Press

Feskanich D, Ziegler RG, Michaud DS, Giovannucci EL, Speizer FE, Willett WC, Colditz GA (2000) Prospective study of fruit and vegetable consumption and risk of lung cancer among men and women. J Natl Cancer Inst 92: 1812-1823 
Fuchs CS, Giovannucci EL, Colditz GA, Hunter DJ, Stampfer MJ, Rosner B, Speizer FE, Willett WC (1999) Dietary fiber and the risk of colorectal cancer and adenoma in women. $N$ Engl J Med 340: 169-176

Guo W, Blot WJ, Li JY, Taylor PR, Liu BQ, Wang W, Wu YP, Zheng W, Dawsey SM, Li B Fraumeni JF Jr (1994) A nested case-control study of oesophageal and stomach cancers in the Linxian nutrition intervention trial. Int J Epidemiol 23: $444-450$

Health Statistics Foundation (2000) Trend of National Hygiene (in Japanese). Tokyo: Health Statistics Foundation

Hennekens CH, Buring JE, Manson JE, Stampfer M, Rosner B, Cook NR, Belanger C, LaMotte F, Gaziano JM, Ridker PM, Willett W, Peto R (1996) Lack of effect of long-term supplementation with beta carotene on the incidence of malignant neoplasms and cardiovascular disease. $N$ Engl J Med 334: $1145-1149$

Hill MJ (1997) Nutrition and human cancer. Ann N Y Acad Sci 833: 68-78

Hirayama T (1978) Epidemiology of breast cancer with special reference to the role of diet. Prev Med 7: 173-195

Hirayama T (1980) Diet and cancer. Nutrition and Cancer 1: 67-81

Hirayama T (1981) A large-scale cohort study on the relationship between diet and selected cancers of digestive organs. Banbury Report 7: Endogenous factors: Gastrointestinal cancer, pp 409-429

Hirayama T (1986) Nutrition and cancer-a large scale cohort study. Prog Clin Biol Res 206: 299-311

Hirayama T (1990) Life-Style and Mortality: a Large-Scale Census-Based Cohort Study in Japan. Vol. 6. Contributions to Epidemiology and Biostatistics. Basel: Karger.

Holick CN, Michaud DS, Stolzenberg-Solomon R, Mayne ST, Pietinen P, Taylor PR, Virtamo J, Albanes D (2002) Dietary carotenoids, serum betacarotene, and retinol and risk of lung cancer in the Alpha-Tocopherol, Beta-Carotene Cohort Study. Am J Epidemiol 156: 536-547

Hunter DJ, Manson JE, Colditz GA, Stampfer MJ, Rosner B, Hennekens CH, Speizer FE, Willett WC (1993) A prospective study of the intake of vitamins $\mathrm{C}, \mathrm{E}$, and A and the risk of breast cancer. $N$ Engl J Med 329: $234-240$

Japanese Epidemiological Association on Cancer (1998) Site-Specific Cancers and Lifestyle: Food and Nutrients in Cancer Prevention Among Japanese. Fukuoka: Kyushu University

Kato I, Tominaga S, Matsumoto K (1992) A prospective study of stomach cancer among a rural Japanese population: a 6-year survey. Jpn J Cancer Res 83: $568-575$

Kato K, Akai S, Tominaga S, Kato I (1989) A case-control study of biliary tract cancer in Niigata Prefecture, Japan. Jpn J Cancer Res 80: 932-938

Key TJ, Sharp GB, Appleby PN, Beral V, Goodman MT, Soda M, Mabuchi K (1999) Soya foods and breast cancer risk: a prospective study in Hiroshima and Nagasaki, Japan. Br J Cancer 81: 1248-1256

Kobayashi M, Tsubono Y, Sasazuki S, Sasaki S, Tsugane S (2002) Vegetables, fruit and risk of gastric cancer in Japan: a 10-year followup of the JPHC study Cohort I. Int J Cancer 102: 39-44

La Vecchia C, Negri E, Decarli A, D’Avanzo B, Franceschi S (1988) Risk factors for hepatocellular carcinoma in northern Italy. Int J Cancer 42: $872-876$

Le Marchand L, Murphy SP, Hankin JH, Wilkens LR, Kolonel LN (2000) Intake of flavonoids and lung cancer. J Natl Cancer Inst 92: 154-160

Michaud DS, Feskanich D, Rimm EB, Colditz GA, Speizer FE, Willett WC, Giovannucci E (2000) Intake of specific carotenoids and risk of lung cancer in 2 prospective US cohorts. Am J Clin Nutr 72: 990-997

Michels KB, Edward G, Joshipura KJ, Rosner BA, Stampfer MJ, Fuchs CS, Colditz GA, Speizer FE, Willett WC (2000) Prospective study of fruit and vegetable consumption and incidence of colon and rectal cancers. J Natl Cancer Inst 92: 1740 - 1752

Nagano J, Kono S, Preston DL, Moriwaki H, Sharp GB, Koyama K, Mabuchi $\mathrm{K}$ (2000) Bladder-cancer incidence in relation to vegetable and fruit consumption: a prospective study of atomic-bomb survivors. Int $J$ Cancer 86: $132-138$

Omenn GS, Goodman GE, Thornquist MD, Balmes J, Cullen MR, Glass A, Keogh JP, Meyskens FL, Valanis B, Williams JH, Barnhart S, Hammar S (1996) Effects of a combination of beta carotene and vitamin A on lung cancer and cardiovascular disease. N Engl J Med 334: 1150-1155

Payne S (2001) 'Smoke like a man, die like a man'?: a review of the relationship between gender, sex and lung cancer. Soc Sci Med 53: 1067-1080

Pierce DA, Shimizu Y, Preston DL, Vaeth M, Mabuchi K (1996) Studies of the mortality of atomic bomb survivors. Report 12, Part I. Cancer: 1950 1990. Radiat Res 146: 1-27
Radiation Effects Research Foundation (1978) Mail Questionnaire Survey for Epidemiologic Data on the Life-Span Study Extended Sample, 1978. Hiroshima: Radiation Effects Research Foundation

Rohan TE, Howe GR, Friedenreich CM, Jain M, Miller AB (1993) Dietary fiber, vitamins $\mathrm{A}, \mathrm{C}$, and $\mathrm{E}$, and risk of breast cancer: a cohort study. Cancer Causes Control 4: 29-37

SAS Institute (2001) SAS/STAT User's Guide, Version 8. Cary, NC: SAS Institute Inc

Sauvaget C, Allen N, Hayashi M, Spencer E, Nagano J (2002) Validation of a food frequency questionnaire in the Hiroshima/Nagasaki Life Span Study. J Epidemiology 12: 394-401

Schatzkin A, Lanza E, Corle D, Lance P, Iber F, Caan B, Shike M, Weissfeld J, Burt R, Cooper MR, Kikendall JW, Cahill J (2000) Lack of effect of a low-fat, high-fiber diet on the recurrence of colorectal adenomas. Polyp Prevention Trial Study Group. N Engl J Med 342: 1149-1155

Shibata A, Mack TM, Paganini-Hill A, Ross RK, Henderson BE (1994) A prospective study of pancreatic cancer in the elderly. Int J Cancer 58: 46 49.

Singh PN, Fraser GE (1998) Dietary risk factors for colon cancer in a lowrisk population. Am J Epidemiol 148: $761-774$.

Smith-Warner SA, Spiegelman D, Yaun SS, van den Brandt PA, Folsom AR, Goldbohm RA, Graham S, Holmberg L, Howe GR, Marshall JR, Miller AB, Potter JD, Speizer FE, Willett WC, Wolk A, Hunter DJ (1998) Alcohol and breast cancer in women: a pooled analysis of cohort studies. JAMA 279: $535-540$

Steinmetz KA, Kushi LH, Bostick RM, Folsom AR, Potter JD (1994) Vegetables, fruit, and colon cancer in the Iowa Women's Health Study. Am J Epidemiol 139: 1 - 15.

Steinmetz KA, Potter JD (1991) Vegetables, fruit, and cancer. I. Epidemiology. Cancer Causes Control 2: 325-357

Steinmetz KA, Potter JD (1996) Vegetables, fruit, and cancer prevention: a review. J Am Diet Assoc 96: 1027-1039

Stolzenberg-Solomon RZ, Pietinen P, Taylor PR, Virtamo J, Albanes D (2002) Prospective study of diet and pancreatic cancer in male smokers. Am J Epidemiol 155: 783-792

Terry P, Giovannucci E, Michels KB, Bergkvist L, Hansen H, Holmberg L, Wolk A (2001) Fruit, vegetables, dietary fiber, and risk of colorectal cancer. J Natl Cancer Inst 93: 525-533.

Tominaga S (1985) Cancer incidence in Japanese in Japan, Hawaii, and western United States. Natl Cancer Inst Monogr 69: 83-92

Verhoeven DT, Assen N, Goldbohm RA, Dorant E, van't Veer P, Sturmans F, Hermus RJ, van den Brandt PA (1997) Vitamins C and E, retinol, betacarotene and dietary fibre in relation to breast cancer risk: a prospective cohort study. Br J Cancer 75: 149-155

Voorrips LE, Goldbohm RA, van Poppel G, Sturmans F, Hermus RJ, van den Brandt PA (2000) Vegetable and fruit consumption and risks of colon and rectal cancer in a prospective cohort study: The Netherlands Cohort Study on Diet and Cancer. Am J Epidemiol 152: $1081-1092$.

World Cancer Research Fund and American Institute for Cancer Research (1997) Food, Nutrition and the Prevention of Cancer: A Global Perspective. Washington: American Institute for Cancer Research

World Health Organization (1977) International Classification of Diseases, 9th Revision. Geneva: WHO

Wynder EL (1977) The dietary environment and cancer. J Am Diet Assoc 71: $385-392$

Yu MW, Hsieh HH, Pan WH, Yang CS, Chen CJ (1995) Vegetable consumption, serum retinol level, and risk of hepatocellular carcinoma. Cancer Res 55: $1301-1305$

Zatonski WA, La Vecchia C, Przewozniak K, Maisonneuve P, Lowenfels AB, Boyle P (1992) Risk factors for gallbladder cancer: a Polish case - control study. Int J Cancer 51: 707-711

Zhang YH, Kramer TR, Taylor PR, Li JY, Blot WJ, Brown CC, Guo W, Dawsey SM, Li B (1995) Possible immunologic involvement of antioxidants in cancer prevention. Am J Clin Nutr 62: 1477S-1482S

Zheng W, McLaughlin JK, Gridley G, Bjelke E, Schuman LM, Silverman DT, Wacholder S, Co-Chien HT, Blot WJ, Fraumeni Jr JF (1993) A cohort study of smoking, alcohol consumption, and dietary factors for pancreatic cancer (United States). Cancer Causes Control 4: $477-482$

Ziegler RG, Mayne ST, Swanson CA (1996) Nutrition and lung cancer. Cancer Causes Control 7: 157-177 